\title{
Cognitive Rigidity in Adolescence with Tendency to Autoregressive Behavior Model
}

\author{
Elena Azarova ${ }^{1,{ }^{*},}$ Maria Vyshkvyrkina $^{1}$, Dmitriy Vorontsov $^{1}$, Elena Zinchenko ${ }^{1}$, and \\ Ekaterina Nemilova ${ }^{1}$ \\ ${ }^{1}$ Southern Federal University, Bolshaya Sadovaya Str. 105/42, 344006 Rostov-on-Don, Russian \\ Federation
}

\begin{abstract}
The history of studying autoaggressive behavior model and cognitive rigidity is quite extensive and diverse. Nevertheless, the relevance of studying the problem of autoaggression among adolescents has increased significantly in recent decades. Self-harming and selfdestructive behavior has become a fashion trend among the younger generation. The aim of the research is studying of features cognitive rigidity in adolescence with a tendency to autoregressive behavior model. the study involved 65 students of secondary school aged 14-15 years $(\mathrm{M}=14,4 ; \mathrm{SD}=0,8)$. The following methods were used: «Tendencies to deviant behavior» (A.N. Orel), The Stroop Color and Word Test, besides statistical techniques (descriptive statistics, Mann Whitney $U$ test, Spearman rank correlation coefficient). As the result of the research it was proved that adolescents who are prone to autoaggressive behavior model, the level of cognitive rigidity is higher, in comparison with adolescents who are not inclined to self-destructive behavior. There was also discovered a positive relationship between the degree of propensity for autoaggressive behavior model and the level of cognitive rigidity. The prospects of the research cover the study of the personal characteristics of children and parents, the styles of family education that contribute to the formation and development of cognitive rigidity, the tendency to autoaggressive behavior. The results of the research can be used in the organization of psychological and pedagogical support of adolescents and their families.
\end{abstract}

\section{Introduction}

At present days, the problem of rigid personality is attracting more attention of scientists. On the one hand, the number of crimes both against the personality of another person and against one's own personality, and on the other hand - with the deterioration of the quality of the educational product in the conditions of digitalization. Mental rigidity does not have a definition that would match all researchers, for several reasons. Firstly, this concept is considered by scientists within the structure of various concepts (G. V. Zalevsky, G. Yu. Aizenk, R. Kettell, I. E. Volpert, etc.), and secondly, there is no solid foundation for

\footnotetext{
*Corresponding author: muha81@list.ru
} 
research, and scientists constantly face difficulties in studying this phenomenon. In our opinion, these difficulties may arise due to the large number of repertory combinations of rigidity with other personality traits, as well as due to the lack of knowledge of the brain mechanisms of rigidity, in particular cognitive.

In psychology, mental rigidity is considered as the inability and unwillingness of the subject of activity to change their behavior in changing conditions, insufficient adaptability of the individual's behavior, stiffness, rigidity, and stereotypy. For example, in the conditions of digitalization and computerization of society, mental rigidity makes it difficult for a person to master digital technologies, prevents the development of their own opinion about the rapid changes that are taking place, and hinders adaptation to a changing lifestyle.

In medical research, rigidity is understood as "a psychopathological state, which is characterized by low mobility of mental processes, inertia of attitudes, impaired switching of speech and thinking, which significantly complicates the adaptation of patients to changing external conditions" [1]. From the point of view of psychiatry, cognitive rigidity plays a special role in various mental disorders. According to some authors, rigidity is directly related, on the one hand, to a critical attitude to the content of their mental reflection, on the other hand, to a critical attitude to the psychotherapeutic process, to drug treatment and its results, as well as to the prospects of social rehabilitation [2-4]. In criminology, a rigid operational attitude is the characteristic handwriting of a criminal. The index of mental rigidity is determined by the convergence of environmental factors and individual personality characteristics.

Traditionally, researchers distinguish between affective, motivational, and cognitive rigidity. The latter is seen as the inability to change behavior and attitude to the environment, at the time when these changes are really happening. At the same time, cognitive rigidity can have various forms, such as perceptual rigidity, fixed attitude (the effect of precedence, priming) and fixed functionality, described by K. Duncker [5].

Cognitive rigidity is one of the causes of destructiveness and group and individual behavior. Cognitive rigidity impedes the success, productivity and creativity of any activity, because it is dominated by the same type of ways to solve problems and overcome problems, as well as stereotypical thinking [6]. The style of thinking is considered rigid if a person, reacting to a situation, relies only on his previous experience, without analyzing the current situation. The coincidence of the current situation and previous experience facilitates any cognitive activity, while the mismatch of new and old information initiates cognitive dissonance, a conflict in which the downward influence of previous knowledge on the process of cognition of a new stimulus is formed, which leads to a distortion of repeated perception.

In clinical psychology, there is a similar but more extensive concept - "inert thinking", which includes a group of syndromes characterized by low mobility of mental processes (viscous thinking, perseverative thinking) [7-9].

Cognitive rigidity is a attachment to certain boundaries that stands in the way of creative search. Creativity lies in rethinking the problem, the ability to look at the "old" "a new look." Binding to boundaries triggers the mechanisms of cognitive rigidity, which manifests itself in the complexity of going beyond the already known, familiar-to where, in fact, insights lie and an endless space of possibilities stretches.

R. Kettell described a special type of personality with high cognitive rigidity. The profile of such a person is characterized by a low level of independence, combined with efficiency [10]. Individuals with cognitive flexibility, on the other hand, are quick-witted, quick to grasp new things, but rarely tolerate restrictions on freedom. At the same time, $\mathrm{M}$. J. Zakraski points out that gifted children are characterized by high emotional tension and high cognitive rigidity, which is manifested in difficulties in changing mental attitudes [11]. 
In reseraches, it has been found that the index of cognitive rigidity depends on the level of motivation, the degree of complexity of tasks, and individual personality characteristics, which are perhaps the main and most poorly studied factor in this context [12]. Numerous studies of the formation of cognitive rigidity in a child indicate the primary role of the type of family relations, parenting style and personal characteristics of parents in this process. In our opinion, the formation of cognitive rigidity and its connection with the autoaggressive behavior of adolescents lies precisely in these factors.

The inability to look at the changed situation with a new perspective and change their behavior in connection with the changing conditions of reality creates a stressful situation for the teenager and, as a compensation for the impotence and inability to survive the defeat productively, the mechanism of autoaggressive behavior is formed. In adolescence, the child is particularly sensitive to their own failure. Research by N. V. Leyfried's research, aimed at studying the ideas of success in people of different ages, revealed that a successful person is a person who is financially secure, has a family and a prestigious job, the possibility of career growth, is able to achieve goals, has a high social status, etc. [13]. These qualities require a person to be able not only to set certain goals, but also to achieve them. But on the way to achieving these goals, there are both predictable and unpredictable obstacles, which require active thinking, cognitive flexibility, and creativity to overcome. But if a person's thinking is rigid, then there are difficulties not only in self-development and self-realization of the individual, in achieving long-term goals and solving complex tasks, but also in activities aimed at meeting basic physiological needs.

E. S. Shneidman believes the presence of autoaggressive manifestations is an escape from unbearable thoughts. V. Frankl explains the tendency to auto-aggressive thinking as a consequence of the loss of the meaning of life. The most extensive and numerous studies of aggression in children and adolescents are presented in psychology. In foreign psychological science, the description and explanation of the essence and nature of human aggression is revealed in the following theories:

- instinctivist concepts (Z. Freud, K. Lorenz) - their proponents believe that innate factors play a decisive role in the occurrence of aggression;

- the theory of frustration (S. Feshbeck, R. Jin, L. Berkowitz, E. Donnerstein, etc.) - its representatives believe that aggression is the result of subjectively or objectively insurmountable barriers that cause a state of frustration or confusion on the way to a particularly desirable goal;

- theories of social learning of aggression (A. Bass, A. Bandura) - scientists who share these views hold the opinion that people are taught pre-set repertoires of violent behavior throughout their lives;

- the theory of social influence (R. B. Smith, R. Brown, J. Tedeschi) - its representatives hold the opinion that violence (the power of coercion) is used to achieve the desired in the case when other methods (the power of persuasion) have already exhausted themselves or they are completely absent, the concept of "coercive force" in this case practically becomes synonymous with the term "aggression"), etc. [14].

In our opinion, these theories are united by a common component - the inability to meet needs, which leads to the emergence of a certain state and the formation of characteristic reactions. In the context of our study, aggressive reactions directed internally are autoaggression.

From the point of view of the content aspects of behavior, the following forms of autoaggression are distinguished: self-harm, eating disorders, chemical addiction, fanatical behavior, autistic behavior, victim behavior, suicidal behavior.

Autoaggression, becoming the main mechanism for responding to complex social situations, detains the formation of productive ways to resolve conflicts, and makes the repertoire of strategies for interacting with people scarce. A teenager, and then an adult, 
does not have sufficient conversation skills, does not know how to formulate and defend their own opinion, more often avoids the negative reaction of others, reducing the possible variability of behavior. Anxiety-suspicious, autistic personality traits are formed, and serious problems arise associated with psychological adaptation in new social groups. In extreme cases, the negative consequence is a weak ability to socialize: young people can abruptly stop the learning process, they experience difficulties in building relationships with the opposite sex, creating their own family.

In the cognitive direction, autoaggression is considered through the action of a certain kind of cognitive distortions, which are characterized by the rigidity of cognitive schemes, dichotomy in thinking and a tendency to globalization. For example, A. Beck and B. Shaw studied self-regulation strategies, cognitive rigidity, attributive style, and the complexity of cognitive styles of autoagressors and proved that individuals who are prone to autoagression are sensitive to situations of uncertainty and are characterized by ineffective emotional control [15]. According to L.I. Antsyferova's autoagression is "maladaptive psychological defenses (coping strategies) that arise in a person in difficult or extreme life conditions, due to the inability to adequately reconsider, re-evaluate the changed social situation" [16].

Each age is remarkable in its own way, each age has its own characteristics and its own difficulties. In adolescence, this is especially obvious. This is the longest transition period. Mental development in adolescence, according to D.B. Elkonin, is characterized by a special social situation of development, leading activity and mental neoplasms. In this age period, communication with peers comes to the fore, any assessment of a teenager by peers becomes much more important than the assessment given to him by teachers and parents. The psyche is characterized by the so-called polarity, or ambivalence, the lack of a clear systematization. The interests of teenagers are extremely unstable. The content of the "adolescent complex" consists of specific behavioral patterns characteristic of this age, a specific set of behavioral reactions to actions from the outside.

The psyche is characterized by the so-called polarity, or ambivalence, the lack of a clear systematization. The interests of teenagers are extremely unstable. The content of the "adolescent complex" consists of specific behavioral patterns characteristic of this age, a specific set of behavioral reactions to actions from the outside.

The reason for the psychological difficulties of a teenager is largely determined by his physiological maturation, which affects the entire psychosomatic system, which is expressed in emotional lability, instability, and sharp mood swings. The peak of emotional instability in boys is manifested at the age of 11-13 years, in girls-13-15 years.

In adolescence, the factors that enhance autoaggressive behavior are: biological, individual - psychological prerequisites, family - as a microsocial factor, mass media and youth pseudo-culture - as macrosocial factors, surrounded social factors.

The reason for the autoaggressive behavior, V. Frankl sees in the loss of the meaning of life, an existential crisis. In a disorganized family, in which there is no harmony, support and all-acceptance of the child, in the presence of biological, individual and psychological prerequisites, as well as the influence of the media and youth pseudo-cultures, the teenager develops aggression, which he directs at himself. Autoaggression does not always manifest itself in its extreme form - suicide, it can be expressed in addictive behavior, when a teenager begins to use psychoactive substances (drugs, alcohol, tobacco smoking), a tendency to risky behavior, promiscuity.

\section{Materials and Methods}

The aim of the research was to study the features of cognitive rigidity of adolescents with a tendency to autoaggression behavior model. 
The study involved 65 students of Secondary School №12 in Bataysk, Rostov region, Russia, 29 of them boys and 36 girls aged $14-15$ years $(\mathrm{M}=14.4$; $\mathrm{SD}=0.8)$.

The following methods were used: «Tendencies to deviant behavior» (A.N. Orel), The Stroop Color and Word Test, besides statistical techniques (descriptive statistics, Mann Whitney U test, Spearman rank correlation coefficient)

The supposion that were tested were that: 1) the degree of severity of cognitive rigidity in adolescents with different degrees of propensity for autoaggression may differ; 2) certain connections may be established between cognitive rigidity and the propensity for autoaggression in adolescents.

At the first stage of our study, 112 adolescents were diagnosed with a tendency to autoaggression behavior model. Based on the results obtained, two empirical groups were identified: adolescents who are prone (32 people) and non-prone (33 people) to autoagresia. At the second stage of the study, cognitive rigidity was diagnosed in the experiential groups.

\section{Results}

Based on the data derived by the results of the methodology aimed at identifying the tendency to autoaggression, it was revealed that the vast majority of the surveyed adolescents $(71.43 \%)$ are not prone to autoaggressive behavior. This reflects the positive side of the process of family education, first of all, the stability of the individual in relation to various temptations (alcohol, drugs). These adolescents may oppose their own opinions to those of a group that, for example, believes that the criteria for adulthood are the use of mind-altering substances. These teenagers are characterized by responsibility as a personal trait. They are positive about themselves as a person, they accept their appearance, in general, they can be satisfied with their abilities and capabilities. They adequately assess themselves. Autoaggression, as a rule, is manifested in people who are displeased with themselves, protesting against the social environment, pressure on them by adults, lack of understanding and trust in the world, despair, hopelessness, etc.

Slightly less than a third of the surveyed $(28.57 \%)$ teenagers are prone to autoaggressive behavior model. That is, in certain situations, this tendency can develop into a willingness to use self-destructive and self-damaging forms of behavior. Autoaggression can manifest itself in direct physical self-harming effects - suicidal attempts, in self-destructive behavior - the use of alcohol, drugs, smoking, the use of psychoactive substances, energy drinks. It can also manifest itself indirectly, in verbal aggression directed against oneself - swearing, insults to oneself. As a rule, these are people who do not know how to get out of difficult life situations in a different way.

In our opinion, we can talk about demonstrative forms of autoaggression - physical self-harm up to suicidal efforts, and sluggish autoaggression, which appears in the modification of one's own body and the use of substances that destroy the body gradually. This form of autoaggression can lead to the formation of a stable form of addictive behavior, when a person is no longer able to get rid of the addiction on their own, and then we should talk about a combination of two types of deviant behavior - autoaggressive and addictive.

Based on the results obtained, two groups were formed from the entire sample: adolescents prone to autoaggression (referred to as A) and adolescents not prone to autoaggression (referred to as $\mathrm{N}$ ).

Further, in the experiential groups, the cognitive style of flexibility/rigidity of cognitive control was diagnosed, which characterizes the ability to change the ways of processing information in the event of a cognitive conflict. 
To test the assumption that there are differences in degree of expression of cognitive rigidity in adolescents with different degrees of propensity for autoaggression, a comparison of the Mann Whitney U test groups was performed (Table 1).

Table 1. Cognitive rigidity of adolescents who are prone and not inclined to autoaggression

\begin{tabular}{|l|l|l|l|l|l|l|}
\hline Test scale / Group & \multicolumn{2}{|l|}{$\begin{array}{l}\text { Group 1 (A) } \\
\mathrm{n}=32\end{array}$} & \multicolumn{2}{l|}{$\begin{array}{l}\text { Group 2 (N) } \\
\mathrm{n}=33\end{array}$} & $\begin{array}{l}\text { Mann } \\
\text { Whitney U } \\
\text { test }\end{array}$ & \multirow{2}{*}{$\mathrm{p}$} \\
\cline { 2 - 6 } & $\mathrm{M}$ & $\sigma$ & $\mathrm{M}$ & $\sigma$ & 119.000 & $0.003^{* *}$ \\
\hline Cognitive rigidity & 26.93 & 11.71 & 17.49 & 18.27 & 11.00 & 0 \\
\hline
\end{tabular}

Note: $* *$ - significance level 0,01

As shown in the table, in the group of adolescents prone to autoaggression, the obtained rigidity value is higher $(\mathrm{M}=26.93)$, in comparison with the values of rigidity in non-prone adolescents $(\mathrm{M}=17.49)$, which indicates a more expressed interference effect and, accordingly, a more pronounced rigidity of cognitive control in the group of adolescents prone to autoaggression. Not much is known about rigidity as a personality trait. However, along with detached behavior, impulsivity, and socio-psychological isolation, scientists consider it to be one of the most characteristic features of a criminal's personality. Rigidity indicates that the affect is stuck, fixed on the same type of objects. In the presence of this quality, the individual is not able to change his behavior in response to a change in the situation. Rigidity affects behavior during the decision-making period. The so-called rigid operational attitude is mainly developed in persons who commit criminal acts. It can be defined as the habit of acting in a stereotypical way, clearly focusing on a given pattern. Template behavior algorithms significantly complicate communication, which can lead to disadaptation subtly.

Freezing behavior, destructive communication attitudes towards other people, and a tendency to autoaggression - all this together, under certain situations, can become a trigger for committing illegal actions. External influences that meet an internal response eventually become certain forms of behavior.

As a result of statistical processing of the obtained data, significant differences in the level of rigidity of adolescents prone and non-prone to autoaggression were revealed. Thus, we can say that the cognitive rigidity of adolescents who are prone to autoaggression is higher in comparison with the cognitive rigidity of adolescents who are not prone to autoaggression.

Testing the supposion of the existence of a dependence between the degree of severity of cognitive rigidity and the propensity for autoaggression was carried out using the Spearman rank correlation coefficient (Table 2).

Table 2. Correlation analysis of indexes of propensity to autoaggression and rigidity.

\begin{tabular}{|l|l|l|l|}
\hline \multicolumn{2}{|l|}{ Variables } & $\begin{array}{l}\mathrm{r}- \\
\text { Spearman }\end{array}$ & $\mathrm{p}$ \\
\hline Cognitive rigidity & Autoaggression & 0,536 & $\begin{array}{l}0,000^{*} \\
*\end{array}$ \\
\hline
\end{tabular}

Note: **-significance level 0,01

The revealed correlations show that the level of autoaggression is positively correlated with the level of rigidity. Consequently, the more expressed the tendency to autoaggression in adolescents, the more pronounced the rigidity of cognitive control.

In the scientific literature, there is a connection between these personality traits, which in addition to being related to each other, are also associated with other personal 
characteristics, traits and properties. Rigidity is associated with anxiety, suspicion, and vindictiveness. Despite the fact that the tendency to autoaggression was identified in the group of adolescents only as a tendency, nevertheless, rigidity as a style of cognitive control was identified as relevant. If propensity is a willingness to switch to certain forms of behavior in certain circumstances, then rigidity, as an identified feature, can influence the strategies of the subject's behavior at the moment. This is a reason to continue the research.

\section{Discussion}

The theoretical analysis of the works, as well as modern empirical researches, shows that the greatest degree of study concerns autoaggressive behavior due to the fact that the basis is aggression and aggressiveness of the individual as a personal trait. Further, in studies that demonstrate an integrative approach to the problem, cruelty as a personal phenomenon is more studied. And rigidity is the least studied. Criminologists and criminal psychologists mainly use it in their research, since it is most often considered as one of the main features of the criminal's personality.

In the modern conditions of devaluation of personal achievements at the level of abilities, the difficult situation in the socio-economic field, the propaganda of aggression and violence in the media, the fascination of young people with the Internet and various gadgets, the problem of alienation and rigidity of young people is becoming more acute. According to the results of the method of J Stroop in the group of adolescents prone to autoaggression, the obtained rigidity values are higher compared to the values of rigidity in adolescents not prone to autoaggression, which indicates a more pronounced interference effect and, accordingly, a more pronounced rigidity of cognitive control in the group of adolescents prone to autoaggression. Statistical processing of the results of our study confirmed significantly significant differences in the level of rigidity of adolescents prone and non-prone to autoaggression. Spearman's correlation analysis revealed that the more pronounced the tendency to autoaggression in adolescents, the more pronounced the rigidity of cognitive control.

Our results are consistent with the conclusions formulated in the works of various authors (M. V. Smirnova, M. I. Maryin, Yu.G. Kasperovich, M. V. Pastukhov [18]; A. A. Yashin [19]; S. S. Brokke, N. I. Landro, V. O. Haaland [20]; K. E. Gilbert, N. A. Tonge, R. J. Thompson [21]; J. P. Stange, S. L. Connolly, T. A. Burke, J. L. Hamilton, E. J. Hamlat, L. Y. Abramson, L. B. Alloy [22]; S. Khan, R. Kausar [23], etc.). In particular, studying cognitive control in suicidal individuals, S. S. Brokke, N. I. Landro, V. O. Haaland found that suicides had lower levels of attention control than suicides who had not attempted suicide. The authors believe that the risk of suicide trying may be associated with poor attention control and higher control of cognitive shift [20]. K. E. Gilbert, N. A. Tonge, and R. J. Thompson, as a result of their research on the dependence between depression, anxiety, and psychological inflexibility, created a model of latent inflexibility that includes perseverative thinking, personality rigidity, and emotional inertia. The authors proved that the formed inflexibility model positively correlates with depression and anxiety, while the relationship with depression is stronger than with anxiety [21]. The relationship between cognitive rigidity and depression was also revealed by J. P. Stange and co-authors. They have shown that cognitive rigidity and perseverance are risk factors for the occurrence of deep depression in adolescents [22].

S. Khan and R. Kausar devoted their research to the study of psychosocial factors of non-suicidal self-harm among adolescents and young adults. The authors found that anger, emotional depression, anger, and various interpersonal problems are significantly positively 
correlated with self-harming, autoaggressive behavior. At the same time, the degree of family cohesion and the ability to cognitive reassessment are negatively correlated with the tendency to self-harm behavior in adolescents and young adults. The authors pay special attention to the fact that the ability to cognitive re-evaluation, i.e., the ability to the capibality to look at the problem from the other side, to develop a new attitude to the situation, mediates the relationship between family cohesion and the tendency to selfharming behavior [23].

\section{Conclusions}

According to A. Bandura, people with" self-efficiency " set more ambitious goals, they are more diligent than other people, more insistent than them, more resistant to defeat. A person who sets a goal for himself, finds the means to achieve it. When a person is engaged in any activity, he has no need for self-harm and self-destruction. Systems thinking, awareness and working with your cognitive limitations, and the ability to see "over" boundaries will be a key, basic skill of the coming decade.

We can use the latest advances in the insighting of the brain and knowledge from the psychology of creativity in order to more harmoniously change the usual "tunnel" models of thinking. One of the most promising areas in the neurophysiology of creativity is the study of how a positive mood increases the creativity of our thinking.

One of the key ways to form and increase flexibility, variability, reduce rigidity and stereotyping is the education system. However, even in this case, the positive effect is not guaranteed, because it depends on several factors, one of the most important of which is the individualization of training. The ideal educational environment should not just form the flexibility of the individual, but, first of all, influence the level of his conscious selfregulation, reflecting the "set rigidity", i.e., the level of self-regulation. a conscious degree of acceptance of the new, understanding and acceptance of the inevitability of both personal changes and the transformation of the surrounding reality, which, in turn, will lead to a decrease in cognitive rigidity.

There are several perspectives for the research of this problem: the study of individual psychological characteristics of significant adults and the style of family education for the formation of cognitive rigidity of the child; the study of individual psychological characteristics of children and adolescents that contribute to / hinder the formation of cognitive rigidity; the development and testing of correctional programs for various age groups.

\section{References}

1. E.Y. Mazur, E.V. Peresko, The study of rigidity (lability) of thinking in psychology students. Bulletin of the Institute Of World Civilizations, 3(34), 48-55 (2019)

2. S.O. Kuznetsova, A.A .Abramova, A.G. Efremov, S.N. Enikolopov, A study of the features of autoaggressive behavior in persons who experienced sexual abuse in childhood. National Journal of Psychology, 3(35), 88-100 (2019) doi:10.11621/npj.2019.0310

3. N.P. Bekhtereva, Yu.L. Gogolitsyn, Yu.D. Kropotov, S.V. Medvedev, Neurophysiological mechanisms of thinking (Nauka, Leningrad, 1985)

4. A.N. Gusev, O.A. Mikhailova, I.S. Utochkin, The role of individual psychological properties of personality in the severity of the phenomenon of blindness to change. Questions of Psychology, 44, 117-127 (2012) 
5. K. Dunker, Psychology of productive (creative) thinking. Experiment and innovation in school, 6, 35-37 (2009)

6. E.S. Romanova, S.Yu. Reshetina, Professional orientation from the standpoint of the concept of self-diagnosis. Applied Psychology, 3, 19-40 (2001)

7. V.M. Bleicher, Disorders of thinking (Health, Kiev, 1983)

8. G.V. Zalevsky, Fixed forms of behavior of individual and group systems (in culture, education, science and pathology) (Tomsk State University, Tomsk, 2004)

9. G.V. Zalevsky, Mental rigidity in norm and pathology (Tomsk State University, Tomsk, 1993)

10. R.B. Cattell, The scientific analysis of personality (Praeger, Baltimore, 1965)

11. M.J. Zakreski, When emotional intensity and cognitive rigidity collide: What can counselors and teachers do? Gifted Child Today, 41(4), 208-216 (2018) doi:10.1177/1076217518786984

12. G.A. Nizharadze, On two types of rigidity in solving intellectual problems. Questions of psychology, 3, 142-145 (1987)

13. T.V. Belashina, D.A. Kobzeva, Autoagression as a predictor of victim behavior of a person. Human psychology in education, 1(2), 26-32 (2020) doi: 10.33910/2686-95272020-2- 1-26-32

14. K. Lorenz, Aggression: the so-called "evil" (AST, Moscow, 2017)

15. E.A. Azarova, Deviations and addictions: an anthropological approach (Foundation of Science and Education, Rostov-on-Don, 2016).

16. L.I. Antsyferova, Personality development and problems of gerontopsychology (Institute of Psychology of the Russian Academy of Sciences, Moscow, 2006)

17. N.P. Fetiskin, V.V. Kozlov, G.M. Manuilov, Socio-psychological diagnostics of personality development and small groups (Institute of Psychotherapy, Moscow, 2002)

18. M.V. Smirnova, M.I. Maryin, Yu.G. Kasperovich, M.V. Pastukhova, Research of personal predictors of self-injurious behavior in the form of bodily modifications. Psychopedagogy in law enforcement, 2(81), 188-196 (2020) doi: 10. 24411/19996241-2020-12010

19. A.A. Yashin, Cognitive rigidity as a factor of insufficient success. Psychology and Psychotechnics, 11, 1146-1157 (2015) doi: 10.7256/2070-8955.2015.11.16968

20. S.S. Brokke, N.I. Landrø, V.Ø. Haaland, Cognitive control in suicide ideators and suicide attempters. Frontiers in Psychology, 11 (2020) doi:10.3389/fpsyg.2020.595673

21. K.E. Gilbert, N.A. Tonge, R.J. Thompson, Associations between depression, anxious arousal and manifestations of psychological inflexibility. Journal of Behavior Therapy $\begin{array}{lll}\text { and Experimental } & \text { Psychiatry, 88-96 }\end{array}$ (2019) https://doi.org/10.1016/j.jbtep.2018.09.006

22. J.P. Stange, S.L. Connolly, T.A. Burke, J.L. Hamilton, E.J. Hamlat, L.Y. Abramson, L.B. Alloy, Inflexible cognition predicts first onset of major depressive episodes in adolescence. Depression and Anxiety, 33(11), 1005-1012 (2016) doi:10.1002/da.22513

23. S. Khan, R. Kausar, Psychosocial factors of non-suicidal self-injury among adolescents and youngadults. Pakistan Journal of Psychological Research, 35(4), 637-655 (2020) doi:10.33824/PJPR.2020.35.4.34 